\title{
¿Qué fueron los Hospitales de Sangre?
}

\author{
Enrique Laval
}

\author{
What represented Blood Hospitals?
}

Programa de Estudios Médicos
Humanísticos.
Pontificia Universidad Católica de Chile.
A sí se denominó a los establecimientos hospitalarios fundados durante la Guerra del Pacífico, _destinados a la atención de los heridos que eran enviados desde el Norte, especialmente a Santiago.

En 1879, se fundó en la capital, el Hospital de Sangre, donado por la familia Matte, ubicado en la calle Lira esquina de Santa Isabel, cuyo jefe fue el profesor Doctor Manuel Barros Borgoño y sus ayudantes los doctores Francisco Puelma Tupper, Vicente Izquierdo y Máximo Cienfuegos. Estos jóvenes cirujanos que recientemente habían estado en Europa, vieron la transformación que experimentaba la Cirugía con la utilización del método antiséptico de Lister, el que consistía en el lavado de las manos de los cirujanos con solución de ácido fénico “débil”, el campo operatorio se limpiaba con solución fenicada "fuerte" y todo el material que iba a estar en contacto con el paciente, también era sometido a la acción del ácido fénico. Además, Lister introdujo el uso de ligaduras de catgut y suturas de seda fenicadas, comenzando a emplear los tubos de drenaje. Este método ya contaba con 12 años de existencia y había experimentado algunas modificaciones en el servicio del propio Lister, en el famoso King's College Hospital de Londres, donde el maestro trabajó entre 1877 y 1893. Todo esto permitió disminuir la alta letalidad de los enfermos con heridas de guerra.

Luego, se fundaron otros Hospitales de Sangre en Santiago: uno en la calle Castro y el otro en la de Agustinas. En el primero también se introdujo el sistema de Lister, con resultados similares a los del Hospital Domingo Matte, mientras que en el de la calle Agustinas siguieron con el antiguo procedimiento de la "esponja y el cerato”, con una letalidad altísima (80\%).

Hay que destacar que en La Serena funcionó un Hospital de Sangre a cargo del doctor Joaquín Zelaya, quien ideó y puso en práctica la irrigación continua con agua de las heridas de guerra infectadas, a la que agregó algunos antisépticos como el hiposulfito de sodio (licor de Labarraque) y el ácido fénico, obteniendo muy buenos resultados.

El doctor Puelma Tupper, en sus "Recuerdos de Medio Siglo”, comentaba lo mucho que costó convencer a la gente de la existencia de los microbios, agregando que "nosotros los médicos jóvenes veíamos los microbios en todas partes, nos creían perturbados, alucinados; en 1879 me caricaturizaron, con una escopeta matando microbios a diestra y siniestra." 